\title{
Psychological distress and its associated factors in health workers during COVID-19 pandemic in Nepal: An online survey
}

\author{
Nirmala Shrestha', Nisha Gurung ${ }^{1}$, Sanju Banstola', Saurabh Kishor Sah', \\ Sharad Koirala ${ }^{1}$, Bimala Sharma*1
}

'Community Medicine Department, Gandaki Medical College and Teaching Hospital, Pokhara

\begin{abstract}
Introduction: Psychological distress among healthcare workers amidst COVID-19 pandemic has emerged as a serious health problem. Understanding its magnitude is crucial to guide policies and interventions to improve their psychological wellbeing. This study assessed the psychological distress and its associated factors among health care workers in Nepal during the COVID-19 pandemic. Methods: A cross-sectional online survey was carried out among 427 health workers currently working in Nepal from April 25 to June 10, 2020. Psychological distress was measured using "The Kessler Psychological Distress Scale" (K10). Descriptive statistics and inferential statistics were computed at a 5\% level of significance. Ethical approval was taken from Nepal Health Research Council. Results: A total of 427 healthcare workers participated in the study. Out of the total participants, 50.4\% were males. Nearly half of the participants were medical doctors (48\%) followed by nurses $(22.2 \%)$, health assistants $(12.2 \%)$ and $61 \%$ were non-government employees. The healthcare workers who experienced symptoms of psychological distress were $28.9 \%$. Out of 123 respondents who had symptoms of psychological distress, $19 \%$ had mild, $7.3 \%$ had moderate and $2.6 \%$ had severe psychological distress. Female healthcare workers were more likely to have psychological distress than males [AOR: 1.75, CI: 1.05-2.92]. Conclusions: Psychological distress in healthcare workers during the COVID-19 pandemic is a matter of serious health concern. This issue demands urgent comprehensive intervention embracing the provision of a supportive environment and protective equipment, screening psychological outcomes and psychological counseling especially targeting female healthcare workers.
\end{abstract}

Keywords: COVID-19 pandemic, healthcare workers, psychological distress.

\section{*Correspondence:}

Dr. Bimala Sharma

Associate Professor, Community Medicine

Department

Gandaki Medical College and Teaching

Hospital, Pokhara, Nepal

Email: bimalasharma@gmail.com

Submitted: May 5, 2021

Accepted: December 2, 2021

To cite: Shrestha N, Gurung N, Banstola S, Sah SK, Koirala S, Sharma B. Psychological distress and its associated factors in health workers during COVID-19 pandemic in Nepal: An online survey. JGMC Nepal. 2021;14(2):146-152. DOI: $10.3126 /$ jgmcn.v14i2.37158

\section{INTRODUCTION}

The new and ongoing coronavirus (COVID-19) pandemic, caused by a new strain of coronavirus (SARS COV 2) was first identified in December 2019 in Wuhan, China. The outbreak was declared a public health emergency of international concern in January $2020^{1}$ and a pandemic in March 2020. ${ }^{2}$ As of November 4, 2020, more than 47.3 million cases worldwide have been confirmed, with more than 1.21 million deaths attributed to COVID-19. ${ }^{3}$ Healthcare workers (HCWs) are always on the frontline, whether it is an elective treatment, a medical emergency, or dealing with a pandemic like COVID-19 in the community setting. This places HCWs and their families at the greatest risk of getting exposed to infection., ${ }^{4,5}$ As of May 132020 , 1004 HCW deaths due COVID-19 has been reported globally ${ }^{6}$ and it is estimated that COVID-19 related HCW fatalities worldwide could be more than 20,000 (28th October). ${ }^{7}$ As of September 2, 2020, over 500 healthcare providers including doctors, nurses and lab technicians have tested positive for SARS-CoV-2 with one death in 
Nepal. ${ }^{8}$ The number is higher because underreporting is unfortunately projected to rise in the coming days. Being at the frontline of COVID-19 outbreak response, health care workers are not only at risk of getting infected but also suffer psychological distress, fatigue, occupational burnout due to long working hours with insufficient infection prevention and control measures, uncertain quarantine period, and fear of contracting the disease to their family members. This problem is exacerbated by growing mistrust among the general population about virus transmission. Health care workers and their family members are wrongfully believed to be vectors of contagion in a community, exposing them to verbal aggression and even physical violence. ${ }^{8,9}$

During crisis, any individual may be affected physically and emotionally as is happening in COVID-19 crisis. A potential threat to an individual's psychological wellness could be uncertainty about the seriousness of the risk, fear of death, and reduced or absence of social interaction. ${ }^{10}$ While these factors should affect the population worldwide, they could have a more severe impact on healthcare workers due to additional worries related to COVID-19 management with insufficient protective gears amid uncertainty and getting stigmatized by society. ${ }^{9,10}$ To date, very little is known about the mental impact on health care providers amid the COVID-19 pandemic in Nepal. Therefore, this study assessed the psychological distress among health care workers during the COVID-19 pandemic and their associated factors.

\section{METHODS}

\section{Study design and study period}

This was an online cross-sectional survey conducted among the health workers currently working in Nepal. The study is a part of a study entitled "Perceived Risk of COVID-19 and Psychological Distress among health workers during the COVID-19 pandemic in Nepal: an online survey". The questionnaire was made available online for six weeks from April 25 to June 10, 2020.

\section{Sampling}

The sample size was calculated based on the formula recommended by Naing et al. (2006), for the prevalence study. ${ }^{11}$ Where, $\mathrm{Z}$ value at confidence interval $95 \%(\mathrm{Z})=$ 1.96, prevalence $(p)=0.50$ and permissible error $(d)=$ 0.05. The calculated sample size was 384. After adding a $10 \%$ non-response rate, the total sample size was 422 . Through an online survey, 432 samples were collected. Five samples were excluded from analysis because they were not health workers or were non-paid workers. A non-random sampling method was applied to select the respondents. The questionnaire was created through google form and the survey link was administered by email or Facebook messenger to health workers working in different government or non-government hospitals and community setting in all seven provinces of Nepal during the COVID-19 pandemic.

\section{Data collection tools and techniques}

The questionnaire included demographic characteristics, direct or indirect contact history of health workers with confirmed or suspected COVID-19 patients, preventive measures used by healthcare workers to protect themselves while handling COVID-19 patients, enabling environment provided by the organization for the management of COVID-19 patients, and psychological distress among healthcare workers.

Demographic variables like age, sex, ethnicity, religion, education level, job cadre, types of organization were included in the questionnaire. Contact with COVID-19 patients or with their relatives or their infected materials in the last 14 days was asked to assess contact history. Psychological distress was measured using "The Kessler Psychological Distress Scale" (K10) ${ }^{12}$ that contains ten questions about emotional state each with a five-level response scale. The measure can be used as a brief screen to identify the level of distress.

Each item is scored from "none of the time" to five "all of the time". The score of 10 items was then summed, yielding a minimum score of 10 and a maximum score of 50 . A low score indicates low levels of psychological distress and high scores indicate high levels of psychological distress. The final scores were categorized into four levels: "Likely to be well (10-19)", "Likely to have the mild disorder (20-24)", Likely to have a moderate disorder (25-29), Likely to have a severe disorder (30-50). For further analytical purpose, "likely to have a mild disorder," "Likely to have a moderate disorder," "Likely to have severe disorder" were grouped as "Likely to have psychological distress' whereas "likely to be well" was categorized as "No psychological distress".

\section{Data analysis}

The data was edited and analyzed using Statistical Package for the Social Sciences (SPSS) version 24.0. Descriptive statistical tools like frequency, percentage, mean, standard deviation were used to express the results. Chi-square test and binary logistic regression were applied. All tests were done at the significance level of $5 \%$ (P value $<0.05$ ). 


\section{Ethical consideration}

The study was reviewed and approved by the ethical review board of the Nepal Health Research Council (Reference number 2191; ERB number 310/2020). Informed consent form was placed on the first page of the online questionnaire form. The objective of the study, statement of confidentiality and autonomy were declared before starting the survey. Written digital consent was obtained from each participant before participation.

\section{RESULTS}

\section{Characteristics of the participants}

Out of 427 respondents, half were male $(n=212,50.4 \%)$, nearly sixty percent $(n=248,58.8 \%)$ were of age group 19 to 29 years with mean age $29.59 \pm 6.14$ (Table 1 ). Majority of them ( $n=393,92 \%)$ followed Hindu religion, nearly three-fourth (70.3\%) were Brahmin/Chhetri. The nuclear family constitutes $63.5 \%$ of respondents. The education level of nearly one-third $(n=135,31.6 \%)$ was Masters and above. Nearly half the participants were medical doctors $(n=205,48 \%)$ followed by nurses $(n=106,22.2 \%)$ and health assistants (12. 2\%). More than sixty percent (61\%) were non-government employees (not shown in the table).

Table 1: Characteristics of the study population $(n=427)$

\begin{tabular}{|c|c|c|}
\hline Characteristics & Number & Percentage \\
\hline \multicolumn{3}{|l|}{ Sex } \\
\hline Male & 212 & 49.6 \\
\hline Female & 215 & 50.4 \\
\hline \multicolumn{3}{|l|}{ Age group ( in years) } \\
\hline $19-29$ & 248 & 58.8 \\
\hline $30-39$ & 143 & 33.9 \\
\hline$>40$ & 31 & 7.3 \\
\hline Missing & 5 & 1.2 \\
\hline \multicolumn{3}{|l|}{ Religion } \\
\hline Hindu & 393 & 92.0 \\
\hline Buddhist and others & 34 & 8.0 \\
\hline \multicolumn{3}{|l|}{ Educational level } \\
\hline Bachelor and below & 292 & 68.4 \\
\hline Masters and above & 135 & 31.6 \\
\hline \multicolumn{3}{|l|}{ Job cadre } \\
\hline Doctors & 205 & 48.0 \\
\hline Nursing professionals & 106 & 24.8 \\
\hline Health assistant and axillary health workers & 65 & 15.2 \\
\hline Laboratory workers & 30 & 7.0 \\
\hline Pharmacy and public health workers & 21 & 4.9 \\
\hline \multicolumn{3}{|l|}{ Psychological Status } \\
\hline Likely to be well & 304 & 71.1 \\
\hline Likely to have a mild disorder & 81 & 19.0 \\
\hline $\begin{array}{l}\text { Likely to have a moderate } \\
\text { disorder }\end{array}$ & 31 & 7.3 \\
\hline $\begin{array}{l}\text { Likely to have a severe } \\
\text { disorder }\end{array}$ & 11 & 2.6 \\
\hline $\begin{array}{l}\text { Mean distress level } \\
(\text { Mean } \pm \text { SD })\end{array}$ & $\begin{array}{c}17.33 \pm \\
5.34\end{array}$ & \\
\hline
\end{tabular}

Psychological status among healthcare workers
The psychological distress among healthcare works was $28.9 \%$. Out of 123 respondents who had symptoms of psychological distress, 19\% had mild disorder, 7.3\% had moderate and $2.6 \%$ had severe psychological distress (Table 1).

Contact history with COVID-19 patients, enabling environment provided to healthcare workers and preventive measures adopted during COVID-19 pandemic

The result showed, only 15 healthcare workers (3.51\%) were found to have close contact with confirmed cases of COVID-19, during our survey. More than three-fourth of healthcare workers rarely or never had access to protective materials like personal protective equipment (76.58\%), soap and water (95.5\%), hand sanitizers (90.39\%), facemasks (85.4\%) in their workplace. Only $29.93 \%$ of health care workers got emotional support from their hospital administration to work against the COVID-19 pandemic. To prevent transmission of the disease, majority of the healthcare workers were always covering mouth while sneezing/coughing (98.36\%), washing hands immediately after coughing/sneezing (91.80\%), after or before examining the patients (93.99\%), and after touching infective materials (99.06\%).

Psychological distress among health care workers and explanatory variables

Table 2 shows that $28 \%$ of females and $19.8 \%$ of male healthcare workers had symptoms of psychological distress. The relationship between gender and psychological distress was statistically significant $(p=0.031)$ while no other sociodemographic characters were found to be significantly associated with psychological distress. Among those who were in close contact with confirmed cases, only one was found to have symptoms of psychological distress. The result showed no significant association between psychological distress among health care workers and their other explanatory variables like contact history, enabling environments and preventive measures adopted by them.

Table 2: Psychological Distress among healthcare workers and explanatory variables

\begin{tabular}{|c|c|c|c|c|c|}
\hline & \multirow[t]{2}{*}{ Variables } & \multicolumn{2}{|c|}{$\begin{array}{c}\text { Psychological } \\
\text { distress } \\
\text { N (\%) }\end{array}$} & \multirow[t]{2}{*}{$\begin{array}{c}\text { Chi } \\
\text { square } \\
\text { value }\end{array}$} & \multirow[t]{2}{*}{$P$ value } \\
\hline & & Yes & No & & \\
\hline \multicolumn{6}{|c|}{ Age group } \\
\hline $19-29$ & & $63(25.4)$ & $185(74.5)$ & 0.186 & 0.666 \\
\hline$\geq 30$ & & 41 (23.6) & $133(76.4)$ & & \\
\hline \multicolumn{6}{|l|}{ Sex } \\
\hline Female & & $\begin{array}{c}62 \\
(28.80)\end{array}$ & $153(71.2)$ & 4.720 & 0.031 \\
\hline $\begin{array}{l}\text { Male } \\
\text { Religion }\end{array}$ & & 42 (19.8) & $170(80.2)$ & & \\
\hline
\end{tabular}




\begin{tabular}{|c|c|c|c|c|}
\hline Hindu & $95(24.2)$ & $298(75.8)$ & 0.090 & 0.765 \\
\hline Buddhist and others & $9(26.5)$ & $25(73.5)$ & & \\
\hline \multicolumn{5}{|l|}{ Ethnicity } \\
\hline Brahmin/Chhhetri & $75(25.0)$ & $225(75.0)$ & 0.388 & 0.544 \\
\hline Newar/Gurung/Magar & $24(25.8)$ & $69(74.2)$ & & \\
\hline Dalit & $5(14.7)$ & $29(85.3)$ & & \\
\hline \multicolumn{5}{|l|}{ Education } \\
\hline Masters and above & $35(25.9)$ & $100(74.1)$ & 0.264 & 0.607 \\
\hline Bachelor and Below & $69(23.6)$ & $223(76.4)$ & & \\
\hline \multicolumn{5}{|l|}{ Types of Family } \\
\hline Nuclear & $67(24.7)$ & $204(75.3)$ & 0.054 & 0.816 \\
\hline Extended/joint & 37 (23.7) & $118(76.3)$ & & \\
\hline \multicolumn{5}{|c|}{$\begin{array}{l}\text { Have an adequate supply of appropriate } \\
\text { personal protective equipment }\end{array}$} \\
\hline Sometimes & $25(25)$ & $75(75)$ & 0.029 & 0.864 \\
\hline Rarely/Never & 79 (24.2) & $248(75.8)$ & & \\
\hline \multicolumn{5}{|c|}{$\begin{array}{l}\text { Have access to soap and water when } \\
\text { needed }\end{array}$} \\
\hline Sometimes & $4(21.1)$ & $15(78.9)$ & 0.118 & $1(\mathrm{~F})$ \\
\hline Rarely/Never & $\begin{array}{c}100 \\
(24.5)\end{array}$ & $308(75.5)$ & & \\
\hline \multicolumn{5}{|c|}{$\begin{array}{l}\text { Have access to hand sanitizer when } \\
\text { needed }\end{array}$} \\
\hline Sometimes & $11(26.8)$ & $30(73.2)$ & 0.151 & 0.698 \\
\hline Rarely/Never & $93(24.1)$ & $293(75.9)$ & & \\
\hline \multicolumn{5}{|c|}{ Have access to face marks when needed } \\
\hline Sometimes & $16(25.8)$ & 46 (74.2) & 0.083 & 0.774 \\
\hline Rarely/Never & $88(24.1)$ & $277(75.9)$ & & \\
\hline \multicolumn{5}{|c|}{$\begin{array}{l}\text { Get emotional support from the } \\
\text { organization to work against COVID-19 }\end{array}$} \\
\hline Sometimes & $28(24.3)$ & 87 (75.7) & .001 & 0.998 \\
\hline Rarely/Never & $76(24.4)$ & $236(75.6)$ & & \\
\hline \multicolumn{5}{|c|}{ Handled fever cases in the last 14 days } \\
\hline yes & $71(26.7)$ & $195(73.3)$ & 2.089 & 0.148 \\
\hline No & $33(20.5)$ & $128(79.5)$ & & \\
\hline \multicolumn{5}{|c|}{ Had close contact with a confirmed case } \\
\hline Yes & $1(6.7)$ & $14(93.3)$ & 2.640 & $0.131(\mathrm{~F}$ \\
\hline No & $\begin{array}{c}103 \\
(25.0)\end{array}$ & $309(75.0)$ & & \\
\hline \multicolumn{5}{|c|}{$\begin{array}{l}\text { Had indirect contact (infected } \\
\text { materials) with confirmed cases. }\end{array}$} \\
\hline Yes & $14(24.6)$ & $43(75.4)$ & 0.002 & 0.969 \\
\hline No & $90(24.3)$ & $280(75.7)$ & & \\
\hline \multicolumn{5}{|c|}{$\begin{array}{l}\text { Wearing a mask regardless of the } \\
\text { presence or absence of symptoms. }\end{array}$} \\
\hline Always/Most of the time & $99(24.6)$ & $304(75.4)$ & 0.171 & 0.679 \\
\hline Sometime/rarely & $5(20.8)$ & 19 (79.2) & & \\
\hline \multicolumn{5}{|c|}{$\begin{array}{l}\text { Washing hands before and after } \\
\text { examining patients. }\end{array}$} \\
\hline Always/Most of the time & $97(24.2)$ & $304(75.8)$ & 0.099 & 0.753 \\
\hline Sometime/rarely & $7(26.9)$ & 19 (73.1) & & \\
\hline \multicolumn{5}{|c|}{$\begin{array}{l}\text { Wearing PPE during handling } \\
\text { COVID-19 cases/suspected cases/ } \\
\text { contacts of cases. }\end{array}$} \\
\hline Always/Most of the time & $66(22.1)$ & 233 (77.9) & 2.820 & 0.093 \\
\hline Sometime/rarely & $38(29.7)$ & $90(70.3)$ & & \\
\hline
\end{tabular}

$\mathrm{P}$ value significant at $<0.05$; F- Fischer's exact test

\section{Multivariate Analysis}

Binary logistic regression revealed that odds of psychological distress was found to be 1.75 times higher among female healthcare workers [AOR 1.75; 95\%CI: 1.05- 2.92] when compared to male. The association was statistically significant (p-value- 0.032). Contact history with COVID-19 patients, enabling environment and preventive measures adopted during the Covid-19 pandemic was found to have no significant association with the psychological distress of health care workers (Table 3).
Table 3: Relation of psychological distress of healthcare workers with explanatory variables

\begin{tabular}{|c|c|c|}
\hline $\begin{array}{l}\text { Variables } \\
\end{array}$ & AOR (95\%Cl) & p-value \\
\hline \multicolumn{3}{|l|}{ Age-group* (5 cases missing) } \\
\hline $19-29$ & $1.09(0.57-2.87)$ & 0.794 \\
\hline 30 and above & 1 & \\
\hline \multicolumn{3}{|l|}{ Sex } \\
\hline Female & $\begin{array}{l}1.75(1.054- \\
2.92)\end{array}$ & 0.032 \\
\hline Male & 1 & \\
\hline \multicolumn{3}{|l|}{ Religion } \\
\hline Hindu & $0.85(0.33-2.19)$ & 0.750 \\
\hline Buddhists and others & 1 & \\
\hline \multicolumn{3}{|l|}{ Ethnicity } \\
\hline Brahmin/ Chhetri & $1.67(0.56-4.91)$ & 0.349 \\
\hline Newar/ Gurung/ Magar & $1.71(0.56-5.23)$ & 0.346 \\
\hline Dalit & 1 & \\
\hline \multicolumn{3}{|l|}{ Types of family } \\
\hline Nuclear & $1.00(0.60-1.66)$ & 0.981 \\
\hline Joint/ extended & 1 & \\
\hline \multicolumn{3}{|l|}{ Education Level } \\
\hline Bachelor and below & $1.26(0.66-2.41)$ & 0.470 \\
\hline Masters and above & 1 & \\
\hline \multicolumn{3}{|l|}{ Job Cadre } \\
\hline Doctors/ Nurse/ ANM/ Lab worker & $0.64(0.35-1.17)$ & 0.151 \\
\hline HA/ AHW/ Pharmacist/ Public health & 1 & \\
\hline \multicolumn{3}{|c|}{$\begin{array}{l}\text { Have an adequate supply of appropriate personal } \\
\text { protective equipment at work }\end{array}$} \\
\hline Sometimes & $1.11(0.64-1.92)$ & 0.690 \\
\hline Rarely/Never & 1 & \\
\hline \multicolumn{3}{|c|}{ Have access to soap and water when needed } \\
\hline Sometimes & $1.01(0.29-3.54)$ & 0.981 \\
\hline Rarely/Never & 1 & \\
\hline \multicolumn{3}{|c|}{ Have access to hand sanitizer when needed } \\
\hline Sometimes & $1.20(0.54-2.66)$ & 0.652 \\
\hline Rarely/Never & 1 & \\
\hline \multicolumn{3}{|c|}{ Have access to face marks when you needed } \\
\hline Sometimes & $0.96(0.48-1.92)$ & 0.923 \\
\hline Rarely/Never & 1 & \\
\hline \multicolumn{3}{|c|}{$\begin{array}{l}\text { Get emotional support from the organization to } \\
\text { work against COVID-19 }\end{array}$} \\
\hline Sometimes & $0.96(0.56-1.65)$ & 0.904 \\
\hline Rarely/Never & 1 & \\
\hline \multicolumn{3}{|l|}{ Handled fever cases in the last 14 days } \\
\hline yes & $1.50(0.90-2.50)$ & 0.116 \\
\hline No & 1 & \\
\hline \multicolumn{3}{|c|}{$\begin{array}{l}\text { Had close contact with a confirmed case in the } \\
\text { last } 14 \text { days }\end{array}$} \\
\hline Yes & $0.35(0.03-3.30)$ & 0.366 \\
\hline No & 1 & \\
\hline \multicolumn{3}{|c|}{$\begin{array}{l}\text { Had indirect contact (infected materials)with } \\
\text { confirmed cases }\end{array}$} \\
\hline Yes & $1.22(0.58-2.57)$ & 0.591 \\
\hline No & 1 & \\
\hline \multicolumn{3}{|c|}{$\begin{array}{l}\text { Wearing mask regardless of the presence or } \\
\text { absence of symptoms }\end{array}$} \\
\hline Always/Most of the time & $1.22(0.41-3.60)$ & 0.719 \\
\hline Sometimes/rarely & 1 & \\
\hline \multicolumn{3}{|c|}{$\begin{array}{l}\text { Washing hands immediately after coughing, } \\
\text { rubbing the nose, or sneezing }\end{array}$} \\
\hline Always/Most of the time & $2.25(0.81-5.21)$ & 0.118 \\
\hline Sometimes/rarely & 1 & \\
\hline \multicolumn{3}{|c|}{$\begin{array}{l}\text { Washing hands before and after examining } \\
\text { patients }\end{array}$} \\
\hline Always/Most of the time & $0.84(0.31-2.26)$ & 0.742 \\
\hline Sometimes/rarely & 1 & \\
\hline
\end{tabular}

$\mathrm{P}$ value significant at $<0.05$ 


\section{DISCUSSION}

Similar to the past pandemic, COVID-19 represents a threat to individuals' physical and psychological wellbeing. Healthcare workers face several challenges in treating patients with COVID-19: reducing the spread of infection; developing suitable short-term strategies; and formulating long-term plans. ${ }^{13}$

The overall prevalence of psychological distress among healthcare workers in this study was $28.9 \%$ which underscores the grave situation that more than one in four healthcare workers have psychological distress. This finding was similar to the study conducted in Ethiopia $(25.5 \%){ }^{14}$ A recent meta-analysis of 50 studies revealed that psychological distress among healthcare workers was $41 \%$ which was higher than our findings. ${ }^{15}$

The result showed a significantly higher prevalence of psychological distress among female healthcare workers than males (28\% female and $19.8 \%$ male). The finding is slightly lower compared to the study done in China ${ }^{16}$ where $31.6 \%$ of female healthcare worker had symptoms of stress. These findings are supported by a systematic review of 10 studies. ${ }^{17}$ Occupational exhaustion, child responsibility, inequalities in domestic labor could be the reason for high psychological distress among female than male health care workers. In contrast to our findings, a study from Ethiopia ${ }^{14}$ showed male healthcare workers had a higher prevalence of psychological distress than female healthcare workers (male 88.7\%, female 11.3\%). But the association was not significant. The reason may be the female population was lower than the male population, not enough to represent female healthcare workers.

In support of our findings, another hospital-based crosssectional study from China reported a considerable proportion of psychological distress among healthcare workers $(71.5 \%)$ during the COVID-19 pandemic and significantly higher among female healthcare workers compared to males. ${ }^{18}$ The study was conducted in JanuaryFebruary 2020 in Wuhan, China. During this period, cases of COVID-19 exceeded 10,000. Most hospitals were sampled from Wuhan, the origin and epicenter of the epidemic in China. Health facilities were overwhelmed with COVID-19 patients, depletion of personal protective equipment, lack of drugs, feeling of inadequately supported, isolated from family members for an unknown period must have created a stressful environment that might have contributed to higher psychological distress among healthcare workers in China whereas our study was conducted during early phase of the pandemic in April- June 2020 where the COVID cases had just started increasing.

When addressing the provision of enabling environment to healthcare workers by their organization, our result showed that more than seventy percent of the participants rarely or never had access to protective materials like personal protective equipment, soap, and water, sanitizers, and facemask in their workplace. However, the association between enabling environment and psychological distress was not statistically significant. A study done in Ethiopia ${ }^{14}$ showed a higher likelihood of psychological distress among those who had disagreed on having resources like soap and water to wash their hands and the association was found to be statistically significant. Healthcare workers are the ones who witness a shortage of protective materials in their workplace so they must have their face masks and sanitizer to protect themselves. This could be the reason for having low psychological distress among healthcare workers in our study who had said of inadequate provision of enabling environment.

Nearly one-fifth $(23.9 \%)$ of the healthcare worker who had been in contact with suspected cases of COVID-19 and infected material were found to have symptoms of psychological distress. However, our result found no significant relationship between contact history and psychological distress. Our result was consistent with the findings from studies conducted in Spain. ${ }^{19}$

Healthcare workers are well aware that the only way to prevent COVID-19 transmission is to adopt preventive measures such as washing hands, wearing a face mask, etc. Our result showed the majority of the health care workers had adopted various preventive measures while handling patients and their infective material. But PPE was made available to only $56 \%$ of participants. Multivariate analysis revealed that the odds of psychological distress among healthcare workers who had worn PPE while handling fever patients was 10\% less [AOR:0.897;95\% CI:0.5561.447) than those who had not worn PPE. However, the association was found to be not significant. We could not compare our findings due to the unavailability of articles with similar findings.

\section{CONCLUSIONS}

The study revealed that more than one-fourth of health care workers experienced symptoms of psychological distress. Female healthcare workers had higher odds of psychological distress compared to males. More than threefourths of healthcare workers rarely or never had access to protective materials like personal protective equipment, 
soap, hand sanitizers, facemasks in their workplace. However, majority of them managed to adopt various preventive measures while handling fever cases to reduce transmission of COVID-19. Addressing the psychological well-being of HCWs and also considering approaches to improve their mental health is essential. The most practical way to protect healthcare workers is the optimal supply of protective materials in their workplace and emotional support from hospital administration and the Government of Nepal.

\section{LIMITATIONS}

We adopted non-random sampling technique which might have introduced selection bias. The study was conducted during initial period of the pandemic when COVID positive cases ranged from 49 to 4085 . Thus, the outcome may change along with time, increasing number of cases, circulation of mutant variant and experience of management among health workers.

\section{ACKNOWLEDGEMENT}

Author would like to thank all the health workers who participated in the study for their time and responses. We would like to acknowledge Prof. Dr. Bishnu Raj Tiwari, Binita Paudel, Ms. Bindu Malla, Ms. Sushma Singh, Mani Neupane, Gopal Prasad Gautam, Dr. Sanish Gurung and others who helped for the data collection.

CONFLICT OF INTEREST: None declared

SOURCE OF FUNDING: None obtained

\section{REFERENCES}

1. COVID Public Health Emergency of International Concern (PHEIC) Global research and innovation forum: towards a research roadmap [Internet]. 2020. https://www.who.int/publications/m/item/ covid-19-public-health-emergency-of-internationalconcern-(pheic)-global-research-and-innovationforum.

2. Euro surveillance Editorial Team. Updated rapid risk assessment from ECDC on the novel coronavirus disease 2019 (COVID-19) pandemic: increased transmission in the EU/EEA and the UK. https://www. eurosurveillance.org/content/10.2807/1560-7917. ES.2020.25.10.2003121?crawler=true.

3. WHO. Weekly operation update on COVID-19 - 6 November 2020. https://www.who.int/ publications/m/item/weekly-operational-update-on- covid-19---6-november-2020.

4. Rosenbaum L. Facing Covid-19 in Italy-ethics, logistics, and therapeutics on the epidemic's front line. New England Journal of Medicine. 2020;382(20):18735. DOI: 10.1056/NEJMp2005492 PMID: 32187459.

5. Ng K, Poon BH, KiatPuar TH, Shan Quah JL, Loh WJ, Wong YJ, et.al. COVID-19 and the risk to health care workers: a case report. Annals of internal medicine. 2020;172(11):766-7. DOI: 10.7326/L20-0175 PMID:32176257.

6. Gouda D, Singh PM, Gouda P, Goudra B. An overview of health care worker reported deaths during the COVID-19 pandemic. The Journal of theAmerican Board of Family Medicine. 2021;34(Supplement):S244-6. DOI: $\quad$ 10.3122/jabfm.2021.S1.200248 PMID: 33622846. International Council of Nurses. ICN confirms 1,500 nurses have died from COVID-19 in 44 countries and estimates that healthcare worker COVID-19 fatalities worldwide could be more than 20,000.https://www.icn.ch/news/icn-confirms1500-nurses-have-died-covid-19-44-countries-andestimates-healthcare-worker-covid.

7. Awale S. Nepal health workers battle Covid-19 but also stigma. Nepali Times [ Newspaper on the internet]. September 2, 2020. https://www.nepalitimes.com/ here-now/nepal-health-workers-battle-covid-19-butalso-stigma/

8. World Health Organization. WHO calls for healthy, safe and decent working conditions for all health workers, amidst COVID-19 pandemic. World Day for Safety and Health at Work: WHO key facts \& key messages to support the day. 2020 Jul.https://www.who.int/ news/item/28-04-2020-who-calls-for-healthysafe-and-decent-working-conditions-for-all-healthworkers-amidst-covid-19-pandemic.

9. Barbato M, Thomas J. Far from the eyes, close to the heart: Psychological Impact of COVID-19 in a Sample of Italian foreign workers. Psychiatry research. 2020 DOI: 10.1016/j.psychres.2020.113113 PMID: 32450412 .

10. Naing L, Winn T, Rusli BN. Practical issues in calculating the sample size for prevalence studies. Archives of orofacial Sciences. 2006;1:9-14.

11. Andrews G, Slade T. Interpreting scores on the Kessler psychological distress scale (K10). Australian and 
New Zealand journal of public health. 2001;25(6):4947. DOI: 10.1111/j.1467-842X.2001.tb00310.x PMID: 11824981.

12. Shreffler J, Petrey J, Huecker M. The impact of COVID-19 on healthcare worker wellness: A scoping review. Western Journal of Emergency Medicine. 2020 Sep;21(5):1059. DOI: 0.5811/westjem.2020.7.48684 PMID: 32970555.

13. Ambelu A, BirhanuZ, Yitayih Y, Kebede Y, Mecha M,Abafita J, et al. Psychological distress during the COVID-19 pandemic in Ethiopia: an online cross-sectional study to identify the need for equal attention of intervention. Annals of general psychiatry. 2021;20(1):1-0. DOI: 10.1186/s12991-021-00344-4 PMID: 33766076.

14. Krishnamoorthy Y, Nagarajan R, Saya GK, Menon V. Prevalence of psychological morbidities among general population, healthcare workers and COVID-19 patients amidst the COVID-19 pandemic: A systematic review and meta-analysis. Psychiatry research. 2020;293:113382. DOI: $10.1016 /$ j.psychres.2020.113382 PMID: 32829073 .
15. Li G, Miao J, Wang H, Xu S, Sun W, Fan Y, et al. Psychological impact on women health workers involved in COVID-19 outbreak in Wuhan: a cross-sectional study. Journal of Neurology, Neurosurgery \& Psychiatry. 2020;91(8):8957. DOI: 10.1136/jnnp-2020-323134 PMID: 32366684.

16. Shaukat N, Ali DM, Razzak J. Physical and mental health impacts of COVID-19 on healthcare workers: A scoping review. International Journal of Emergency Medicine. 2020;13(1):1-8. DOI: 10.1186/s12245-020-00299-5 PMID: 32689925.

17. Lai J, Ma S, Wang Y, Cai Z, Hu J, Wei N, Wu J, Du H, Chen T, Li $\mathrm{R}$, Tan H. Factors associated with mental health outcomes among health care workers exposed to coronavirus disease 2019. JAMA network open. 2020;3(3):e203976. DOI: 10.1001/jamanetworkopen.2020.3976 PMID: 32202646.

18. Gómez-Salgado J, Domínguez-Salas S, Romero-Martín M, Ortega-Moreno M, García-Iglesias JJ, Ruiz-Frutos C. Sense of coherence and psychological distress among healthcare workers during the COVID-19 pandemic in Spain. Sustainability. 2020;12(17):6855. DOI: 10.3390/ su12176855. 